\title{
Gap vs. Effort: Comparative Study of Sports Attitude of College Students from China and US
}

\author{
Jinchao Li ${ }^{1, *}$ and Xiaobing Luo ${ }^{2}$ \\ ${ }^{I}$ Physical Education College, Huaibei Normal University, Huaibei 235000, Anhui, China; ${ }^{2}$ School of Physical Educa- \\ tion, Central China Normal University, Wuhan 430079, Hubei, China
}

\begin{abstract}
Through survey and literature methods, this paper studies the sports attitude of college students from China and the US, to discuss the constituent elements and different perceptions to sports attitude. The result shows that: Among Chinese college students, male students are more positive to sports than female students. The influence of major is significantly smaller than that of gender, while the uncertainty of sports attitude increases with different majors; Despite the differences in gender and major, American college students hold similar and consistent sports attitude, which is relatively stable and certain, with less students in the middle attitude; Gender difference of Chinese college students is bigger, while the major difference is relatively smaller, which is the opposite of the US; Both Chinese and American college students shared the same top give aspects on sports attitude. The attitude and cognition of sports are similar especially from the perspective of gender and major. The sports attitude of American college students in different gender and different major are relatively more consistent, while there is certain disparity between the sports attitude of Chinese male students and female students.
\end{abstract}

Keywords: College students from China and the US, sports attitude, sports motivation.

\section{INTRODUCTION}

In China, students receive physical education from primary to college. As a important part of higher education system and a key learning period in the development of lifelong sports attitude and the training of sports ability, college sports has been under the spot light of school sports and social sports [1]. College physical education aims to teach more than two sports and more important, to cultivate lifelong sports ability and habit. Therefore, the Sports and Health should "be people-oriented and follow the physical and mental development and interests of college students to adapt to the teaching object and give full play to the students' intelligence advantage, and to serve for their use" [2]. The existing sports reform of China is people-oriented, with attention to the development of the students, while learning from the US on the basis of self development. Physical education curriculum in both countries emphasize "the development of the people", which is illustrated in the following aspects: allowing all the students have fun during physical education and managing several sports related to daily life; focusing on the differences of students and setting different teaching contents and methods on the basis of different personalities; and facilitating comprehensive and lifelong development of the students. This paper provides advises and theoretical basis for the improvement of the teaching quality of college sports, and the decision making on sports management of the college administrative departments, based on selective comparison between college students from China and the US (in different gender and majors).

\section{SUBJECTS AND METHODS}

\subsection{Object of Study}

China: 800 questionnaires were sent out to the 710 students in Hubei Engineering College, with 710 effective questionnaires received. Among them, 348 were from male students and 362 were from female students; 380 were from science and engineering students and 330 were from social science students. The receiving rate was $88.75 \%$, while the efficient rate reached $100 \%$.

The US: 756 questionnaires were sent out to students in Brooklyn college of New York City University, in which 364 were from male students and 392 were from female students, and 329 were from science and engineering students and 427 were from social science students, with efficient rate of $100 \%$.

\subsection{Research Methods}

2.2.1. Questionnaire: The design of the questionnaire is provided by Professor Howard. Z (doctor) in sports and health department of New York City University, in English and Chinese versions.

2.2.2. Literature Literature related to sports attitude from 1994 to 2014 in the database of CNKI were referenced for the research.

2.2.3. Mathematical Statistics: The questionnaires were collected and the statistical data were processed by SPSS19 software. 


\section{RESULTS AND ANALYSIS}

\subsection{Analysis on the Sports Attitude of Chinese College Students}

Based on the 20 questions in the second part of the questionnaire (see attachment), the result of each question was evaluated, with its average score compared in the aspects of gender and major, to discuss the constituent elements and motivation factors of the sports attitude of college students.

\subsubsection{Analysis of the Sports Attitude and Male and Female Chinese College Students}

As is found in the 710 effective questionnaires (see Table 1): For the direct questions (the singular questions in the second part), average scores of male students are higher than female students; while for the indirect questions (the even questions in the second part), average scores of female students are higher than male students; For the top 5 questions with average points over 4 (namely agree or above), the result of the male students is number $5,13,1,9$, and 19 (see a5, a13, a1, a9, and a19 in Table 1), while the result of the female students is number 13, 1, 9, and 6 (see a13, a1, a9, and a6 in the Table 1); The order of the overall samples is number 13, 5, 1, 9, and 19 (see a13, a5, a1, a9, and a19 in Table 1), which is consistent with the result of the male students; Based on the two-side test on male and female students, there are significant differences in number $1,5,7,9$, $10,11,12,13,15,16,18$, and $19(\mathrm{P}<0.01)$.

Table 1. Sports attitude of Chinese male and female students $\mathbf{N}=\mathbf{7 1 0}$.

\begin{tabular}{|c|c|c|}
\hline \multirow[b]{2}{*}{ Gender } & \multirow[b]{2}{*}{ Total } & Average Score \\
\hline & & $\begin{array}{c}\text { a1 a2 a3 a4 a5 a6 a } 7 \text { a8 a9 a10 a11 a12 a13 } \\
\text { a14 a15 a16 a17 a18 a19 a20 }\end{array}$ \\
\hline $\begin{array}{c}\text { Male } \\
\text { Students }\end{array}$ & 348 & $\begin{array}{c}4.2383 .8053 .9594 .0954 .5003 .8624 .187 \\
2.7904 .2243 .3224 .0372 .6214 .4113 .724 \\
\quad 3.8132 .1613 .7241 .8794 .1893 .330\end{array}$ \\
\hline $\begin{array}{l}\text { Female } \\
\text { Students }\end{array}$ & 362 & $\begin{array}{c}4.0723 .8643 .8483 .9143 .9724 .0283 .798 \\
2.8894 .0613 .5833 .5802 .9924 .1273 .624 \\
3.4973 .0583 .6242 .1163 .9193 .467\end{array}$ \\
\hline Total & 710 & $\begin{array}{c}4.1533 .8353 .9034 .0034 .2313 .9463 .989 \\
2.8414 .1413 .4553 .8042 .8094 .2663 .673 \\
3.6522 .6183 .6732 .0004 .0523 .400\end{array}$ \\
\hline $\begin{array}{l}\text { P values } \\
\text { (double } \\
\text { side) }\end{array}$ & & $\begin{array}{c}0.0050 .4470 .1120 .0250 .0000 .0320 .000 \\
0.2390 .0090 .0010 .0000 .0000 .0000 .238 \\
0.0000 .0000 .2380 .0010 .0000 .073\end{array}$ \\
\hline
\end{tabular}

According to the statistics of the average scores of the questionnaires, $40 \%(8 / 20)$ questions were credited over 4 points by the male students, while $20 \%(4 / 20)$ by the female students, and $30 \%(6 / 20)$ by all students, which indicates that male students are more positive than female students in sports [3]. 20\% (4/20) male students hold negative sports attitude, while $15 \%(3 / 20)$ female students in that case, with overall rate of $20 \%(4 / 20)$. In addition, analysis shows that although the students with positive sports attitude are more than those with negative attitude, the students in the variable attitude (between 3 and 4 points) accounted for a large percent, with male students of $40 \%(8 / 20)$, female students of $65 \%(13 / 20)$, and the overall result of $50 \%(10 / 20)$. The result is consistent with that of Zhao Hong in the article "Research on Sports Attitude of College Students and Its Impact" [4]. The result shows that the sports attitude of Chinese college students is uncertain, which will cast significant negative influence on the development of school physical education, the cultivation of students, and the improvement of public health quality, if no suitable school education system or positive sports environment provided.

The Data in red (All 710) - The top five highest scores. -a13, a5, a1, a9, a19.

Top five for male students - a5, a13, a1, a9, a19

Top five for female students - a13, a1, a9, a6, a19

\subsubsection{Differences in Sports Attitude of College Students in Different Major}

As is found in the questionnaires of students in different major (science engineering and social science) (see Table 2): For the direct questions (the singular questions in the second part), except number 17, average scores of the male students are higher than the female students; For the indirect questions (the even questions in the second part), the average score of the female students is higher than the male students, while the high point percentage decreased significantly, with $35 \%$ of the questions lower than the male students. In a word, the influence of major is significantly smaller than the gender; For the top five questions with average points over 4 (namely agree or above), the result of the science engineering students is number 5, 13, 1, 9, and 19 (see a5, a13, a1, a9, and a19); while the result of the social science students is number 13, 1, and 9 (see a13, a1, and a19 in the table); the order of the overall samples is number 13, 5, 1, 9, and 19 (see a13, a5, a1, a9, and a19 in the table), which is consistent with the result of the science engineering students; Based on

Table 2. Sports attitude scores of Chinese students in different majors $N=710$.

\begin{tabular}{|c|c|c|}
\hline \multirow[b]{2}{*}{ Major } & \multirow[b]{2}{*}{ Total } & Average Score \\
\hline & & $\begin{array}{c}\text { a1 a2 a3 a4 a5 a6 a } 7 \text { a8 a9 a10 a11 a12 a13 } \\
\text { a14 a15 a16 a17 a18 a19 a20 }\end{array}$ \\
\hline $\begin{array}{l}\text { Science and } \\
\text { engineering } \\
\text { students }\end{array}$ & 380 & $\begin{array}{c}4.1553 .9053 .9294 .0634 .4503 .9584 .082 \\
2.8924 .1533 .4243 .9292 .7374 .3103 .832 \\
3.7632 .1473 .8322 .0324 .1343 .411\end{array}$ \\
\hline $\begin{array}{l}\text { Social science } \\
\text { students }\end{array}$ & 330 & $\begin{array}{c}4.1513 .7543 .8733 .9333 .9793 .9333 .882 \\
2.7824 .1273 .4913 .6612 .8944 .2153 .491 \\
3.5243 .1613 .4911 .9643 .9583 .388\end{array}$ \\
\hline Total & 710 & $\begin{array}{c}4.1533 .8353 .9034 .0034 .2313 .9463 .989 \\
2.8414 .1413 .4553 .8042 .8094 .2663 .673 \\
3.6522 .6183 .6732 .0004 .0523 .400\end{array}$ \\
\hline $\begin{array}{c}\text { P values } \\
\text { (double side) }\end{array}$ & & $\begin{array}{c}0.9500 .0560 .4230 .1080 .0000 .7510 .004 \\
0.1920 .6850 .3960 .0010 .0470 .0910 .000 \\
0.0010 .0000 .0000 .3300 .0030 .767\end{array}$ \\
\hline
\end{tabular}


the two-side test on students in different majors, there are significant differences in number $5,7,11,14,15,16,17$, and $19(\mathrm{P}<0.01)$.

From the perspective of major, $35 \%(7 / 20)$ of science engineering students hold positive sports attitude (4 points or above), while $15 \%(3 / 20)$ of the social science students hold positive sports attitude. The percentage of the overall samples is $30 \%(6 / 20) ; 25 \%(5 / 20)$ of science engineering students hold negative sports attitude, while $15 \%(3 / 20)$ of social science students hold negative sports attitude. The percentage of the overall samples is $20 \%(4 / 20)$, and the percentage of middle attitude students is $50 \%(10 / 20)$.

Through the analysis, the difference of variable attitude (between 3 and 4 points) students in different majors is more significant, with $70 \%$ for the social science students and $40 \%$ for the science engineering students. Major difference is bigger than gender difference, indicating science engineering students like sports more than the active social science students. Sports attitude scores of the female students are lower than the male students, with insignificant difference. Based on the result and the actual situation of the college, the physical education and extracurricular sports activities failed to cater for the physical and mental features and interests of the female students in the respects of content, organization, and equipment. Sports needs of the female students cannot be satisfied without effective measures [5].

The Data in red - The top five highest scores. -- a13, a5, a1, a9, a19.

Top five for science engineering students - a5, a13, a1, a9, a19

Top five for social science students - a13, a1, a9, a5, a19

\subsection{Analysis on the Sports Attitude of American College} Students in Different Majors and Gender

\subsubsection{Analysis on the Sports Attitude of American College Students in Different Gender}

The same questionnaires were sent out to American college students, with results in Table 3. The result of the 756 questionnaires shows that: The top five questions of the overall samples are number 5, 9, 13, 19, and 1 (a5, a9, a13, a19, a1); the order of the male students is number $5,9,19,1$, and 13 (a5, a9, a19, a1, and a13), while the order of the female student is number $5,9,13,19$, and 1 (a5, a9, a13, a19, and a1). These five questions are direct, which reflects positive sports attitude. As is shown from these data, from the perspective of gender, American college students share high consistency on the cognition and attitude of sports, which may be related to the education method and system in the US [6]. Based on the analysis of the sports attitude of American students in different gender, 40\% (8/20) male students hold positive sports attitude, and $30 \%(6 / 20)$ female students hold positive sports attitude. $35 \%(7 / 20)$ of male students hold negative sports attitude, and the same for female students; $25 \%(5 / 20)$ of male students hold uncertain sports attitude, while the value of the female students is $35 \%(7 / 20)$. Overall samples positive percentage was $30 \%(6 / 20)$, negative percentage was $35 \%(7 / 20)$, and middle attitude percentage was $35 \%(7 / 20)$. The two-side test for male and female students shows that there is significant difference in question $3,8,11$,
15, and $17(\mathrm{P}<0.01)$. Through the analysis, from the perspective of score distribution, male students in the middle variable attitude (between 3 to 4 points) cover four questions, while female students cover 7 questions. The overall average score that is between 3 and 4 points covers 7 questions, which accounts for at most $35 \%$. The sports attitude of American college students is clearer, with smaller percentage of students in middle variable attitude than Chinese college students.

The Data in red - The top five highest scores. - a5, a9, a13, a19, a1.

Top five for male students - a5, a13, a1, a9, a19 a1

Top five questions for female students - a5, a9, a13, a19,

Table 3. Sports attitude of Chinese male and female students $\mathbf{N}=\mathbf{7 1 0}$.

\begin{tabular}{|c|c|c|}
\hline \multirow[b]{2}{*}{ Gender } & \multirow[b]{2}{*}{ Total } & Average Score \\
\hline & & $\begin{array}{c}\text { a1 a2 a3 a4 a5 a6 a7 a8 a9 a10 a11 a12 a13 } \\
\text { a14 a15 a16 a17 a18 a19 a20 }\end{array}$ \\
\hline $\begin{array}{c}\text { Male stu- } \\
\text { dents }\end{array}$ & 364 & $\begin{array}{c}4.2832 .0854 .0771 .8354 .4562 .0114 .187 \\
2.7944 .3322 .4174 .0113 .1214 .2771 .923 \\
3.8963 .6181 .9233 .4504 .2862 .148\end{array}$ \\
\hline $\begin{array}{l}\text { Female } \\
\text { studnets }\end{array}$ & 392 & $\begin{array}{c}4.2422 .0133 .7502 .0104 .4821 .8474 .089 \\
3.1864 .3242 .3773 .6633 .0384 .2811 .824 \\
3.5973 .5971 .8243 .4954 .2632 .071\end{array}$ \\
\hline Total & 756 & $\begin{array}{c}4.2622 .0483 .9071 .9264 .4691 .9264 .136 \\
2.9974 .3282 .3973 .8313 .0784 .2791 .872 \\
3.7413 .6071 .8723 .4734 .2742 .108\end{array}$ \\
\hline $\begin{array}{l}\text { P values } \\
\text { (double } \\
\text { side) }\end{array}$ & & 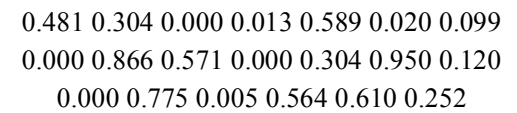 \\
\hline
\end{tabular}

\subsubsection{Differences in Sports Attitude of American College Students in Different Major}

The result (see Table 3 ) of the analysis on the sports attitude of students in different majors shows that: Top five questions based on average score are number 5, 9, 13, 19, and $1(\mathrm{a} 5, \mathrm{a} 9, \mathrm{a} 13, \mathrm{a} 19, \mathrm{a} 1$.$) ; the order for the science engi-$ neering students is 5, 1, 9, 19, and 13 (a5, a1, a9, a19, a13.); and the order for the social science students is 5, 9, 13, 19, and 1 (a5, a9, a13, a19, a1.). Based on the analysis of the sports attitude of American students in different majors, $40 \%$ (8/20) science engineering students hold positive sports attitude, and 30\% (6/20) social science students hold positive sports attitude. $35 \%(7 / 20)$ science engineering students hold negative sports attitude, and the same for social science students. $25 \%(5 / 20)$ of science engineering students hold uncertain sports attitude, while $35 \%$ of social science students hold uncertain sports attitude. The overall percentage of positive attitude is $30 \%(6 / 20)$, the negative percentage is $35 \%(7 / 20)$, and the middle variable percentage is $35 \%(7 / 20)$. From the perspective of different majors, their share high degree of similarity and consistency in cognitive abilities and physical attitude sports. The test to the average 
scores of different majors shows that there is significant differences in question $3,8,11,12,15,16,17$, and 18 $(\mathrm{P}<0.01)$.

The Data in red - The top five highest scores. - a5, a9, a13, a19, a1.

Top five for science engineering students - a5, a1, a9, a19, a13

Top five for social science students -a5, a9, a13, a19, a1

Table 4. Sports attitude scores of American students in different majors $\mathbf{N}=\mathbf{7 5 6}$.

\begin{tabular}{|c|c|c|}
\hline \multirow[b]{2}{*}{ Major } & \multirow[b]{2}{*}{ Total } & Average Score \\
\hline & & $\begin{array}{c}\text { a1 a2 a3 a4 a5 a6 a7 a8 a9 a10 a11 a12 a13 } \\
\text { a14 a15 a16 a17 a18 a19 a20 }\end{array}$ \\
\hline $\begin{array}{l}\text { Science and } \\
\text { engineering } \\
\text { students }\end{array}$ & 329 & $\begin{array}{c}2.0794 .1431 .8664 .4774 .4192 .0304 .258 \\
2.8024 .4012 .3624 .0363 .0554 .3251 .878 \\
\quad 3.9123 .6323 .2013 .5144 .3372 .085\end{array}$ \\
\hline $\begin{array}{l}\text { Social science } \\
\text { students }\end{array}$ & 427 & $\begin{array}{c}4.1412 .0233 .7261 .9724 .4641 .8454 .042 \\
3.1474 .2722 .4243 .6723 .0964 .2441 .866 \\
3.6093 .5882 .9553 .4434 .2252 .126\end{array}$ \\
\hline Total & 756 & $\begin{array}{c}4.2622 .0483 .9071 .9264 .4691 .9264 .136 \\
2.9974 .3282 .3973 .8313 .0784 .2791 .872 \\
3.7413 .6073 .0623 .4734 .2742 .108\end{array}$ \\
\hline $\begin{array}{l}\text { P values (dou- } \\
\text { ble side) }\end{array}$ & & $\begin{array}{c}0.0000 .4340 .0000 .1390 .7820 .0110 .000 \\
0.0000 .0100 .3840 .0000 .6110 .1020 .853 \\
0.0000 .5530 .0010 .3600 .0130 .542\end{array}$ \\
\hline
\end{tabular}

\section{DIFFERENCE BETWEEN THE ATTITUDE OF CHINESE AND AMERICAN COLLEGE STUDENTS}

As is shown in Table 5, both Chinese and American college students shared the same top give aspects on sports attitude. The attitude and cognition of sports are similar especially from the perspective of gender and major. The sports attitude of American college students in different gender and different major shares high consistency, while there is certain disparity between that of Chinese college students [8]. The result from the perspective of major is similar with that of the gender, i.e. the result of the American students is consistent, while there is certain disparity of that of Chinese students. Tables 1-4 showed the two-side test result of American and Chinese college students in different gender and majors: There is significant difference of average scores in question $1,5,7,9,10,11,12,13,15,16,18$, and 19 for Chinese female and male students $(\mathrm{P}<0.01)$, while significant difference of average scores in question $5,7,11,14,15$, $16,17,19(\mathrm{P}<0.01)$. The two-side test for male and female students shows that there is significant difference in question $3,8,11,15$, and $17(\mathrm{P}<0.01)$. The test to the average scores of different majors shows that there is significant differences in question $3,8,11,12,15,16,17$, and $18(\mathrm{P}<0.01)$. Therefore, the gender difference of the Chinese college students is larger while the major difference is smaller, which is the opposite of the American college students. Sports attitude of
American female students is stronger than that of Chinese female college students. The difference is significant. The reason may includes: the limitation of family, community, school cognitive ability to sports, the pressure of further study and employment, the deduction of sports time by school and parents, the passive receiving of physical education rather than active pursuant, and the idea of reducing sports time for academic learning to earn the appreciation from school, parents, community, and society [7].

Table 5. Comparison between the top five questions of college students from China and the US.

\begin{tabular}{|c|c|c|}
\hline \multirow{2}{*}{ Classification } & $\begin{array}{c}\text { Chinese College } \\
\text { Students }\end{array}$ & $\begin{array}{c}\text { American College } \\
\text { Students }\end{array}$ \\
\cline { 2 - 3 } & $\mathbf{1 2 3 4 5}$ & $\mathbf{1 2 3 4 5}$ \\
\hline \hline Male students & a5 a13 a1 a9 a19 & a5 a9 a19 a1 a13 \\
\hline Female students & a13 a1 a9 a6 a19 & a5 a9 a13 a19 a1 \\
\hline $\begin{array}{c}\text { Science engineering } \\
\text { students }\end{array}$ & a5 a13 a1 a9 a19 & a5 a1 a9 a19 a13 \\
\hline Social science students & a13 a1 a9 a5 a19 & a5 a9 a13 a19 a1 \\
\hline Total & a13 a5 a1 a9 a1 & a5 a9 a13 a19 a1 \\
\hline
\end{tabular}

\section{CONCLUSION}

(1) Among Chinese college students, male students are more positive to sports than female students.

(2) The influence of major is significantly smaller than that of gender, while the uncertainty of sports attitude increases with different majors;

(3) Despite gender and major, American college students shared high degree of similarity and consistency in the cognitive ability and sports attitude, which is relatively stable and clear. The student in middle attitude is smaller in proportion than Chinese students.

(4) The gender difference of the Chinese college students is larger while the major difference is smaller, which is the opposite of the American college students.

(5) Both Chinese and American college students shared the same top give aspects on sports attitude. The attitude and cognition of sports are similar especially from the perspective of gender and major. The sports attitude of American college students in different gender and different major shares high consistency, while there is certain disparity between that of Chinese college students. From the perspective of major, American students shows more consistency, while the Chinese students shows more disparity.

\section{CONFLICT OF INTEREST}

The authors confirm that this article content has no conflict of interest.

\section{ACKNOWLEDGEMENTS}

Declared none. 


\section{REFERENCES}

[1] G. Jiang, "Analysis on sports attitude and leisure behavior of college students in Hunan province," Academic Journal of Shanghai Physical Education Institute, vol. 10, no. 5, pp. 106-110, 2005.

[2] Z. Pan, "Research on sports attitude, interest, and motivation of college students in Liaoning province" Academic Journal of Shandong Physical Education Institute, vol. 12, no. 6, pp. 122-124, 2005.

[3] X. Liu, "Research on sports attitude of Chinese college students," Sports Adult Education, vol. 6, no. 3, pp. 33-35, 2008.

[4] H. Zhao, "Research on sports attitude of college students and its impact," Academic Journal of Guangzhou Physical Education Institute, vol. 26, no. 3, pp. 120-122, 2006.
[5] W. Wang, "On sports attitude and behavior of Chinese science engineering college students," Physical Education, vol. 11, no. 2, pp. 107-110, 2004

[6] Z. Pan, M. Sun, and X. Li, "Research on attitude and motivation of college students to sports activities," Academic Journal of Beijing Physical Education University, vol. 12, no. 28, pp. 1636-1637, 2005.

[7] H. Fan, "Research on attitude and behavior of college students on sports activities," Academic Journal of Tianjin Physical Education Institute, vol. 3, no. 18, pp. 89-90, 2003.

[8] N. Zou, "Comparative research on sports attitude between Changchun college students and Boston college students and its impact," Master Thesis. Library of Northeast Normal University, vol. 7, 2008.

(C) Li and Luo; Licensee Bentham Open.

This is an open access article licensed under the terms of the (https://creativecommons.org/licenses/by/4.0/legalcode), which permits unrestricted, noncommercial use, distribution and reproduction in any medium, provided the work is properly cited. 